\title{
Almanya'daki Göçmen Gençlerin Eğitim ve İssizlik Sorunları
}

Gülay TOKSÖZ(*)

$\mathrm{M}$ odern toplumlarda çalışma tüm toplumsal ve bireysel yaşamın merkezi haline gelmiş olup, bireyin konumu esas olarak sahip olduğu iş tarafından belirlenmekte ve birey geçimini işi aracılığıyla sağlamaktadır. Çalışma sadece toplumun maddi üretimine değil manevi üretimine de hizmet etmekte, aynı şekilde bireyler çalışmayla sadece maddi geçimlerini temin etmekle kalmayıp aynı zamanda toplumsal konumlarını edinmekte ve ilişkilerini kurmaktadır. Çalışma bireylerin toplumsal kimliklerini geliştirmeleri ve gerçekleştirmeleri için gereklidir. Ancak 1980'lerden bu yana ekonomik krizle birlikte artan işsizlik bireyler açısından toplum içindeki yerlerini ve kişiliklerini neye göre tanımlayacakları konusunda ciddi sorunlar yaratmaktadır. Toplumsal refahtan pay almanın istihdama katılmaya bağlı olduğu bir toplum örgütlenmesinde, işgücü piyasasına girdiği andan itibaren işsiz kalanlar açısından ciddi yoksulluk ve dışlanma sorunları doğmaktadır. Batı Avrupa ülkelerindeki göçmen gençlerin durumunu bu perspektiften değerlendirmek önem taşımaktadır.

Almanya'da işgücü piyasasının mevcut durumuna göçmenler açısından bakıldığında şunlar görülmektedir:

- Demografik gelişmelere ve net göç hareketlerine bağlı olarak göçmen işgücü arzında hızlı bir artış vardır,

- Genel ekonomik işleyiş işgücünü talebini bu arza karşılık düşecek biçimde artırmamaktadır,

(•) Doç. Dr., A.Ü. SBF ÇEEİ Bölümü 
- Göçmenler ekonominin yeniden yapılanma sürecinden Almanlara kıyasla çok daha fazla olumsuz etkilenmiş ve istihdamın imalat sektöründen hizmetler sektörüne kayması sonucu ya hizmetler sektöründe düşük ücretli işler bulabilmiş ya da işsiz kalmışlardır,

- Göçmenlerin eğitim sistemine katılım ve vasıflılık düzeyi ortalamada çok düşük olduğu için ekonomik gelişmenin yaşandığı alanlarda bile yabancıların durumları Almanlara kıyasla düzelmemektedir (Hönekopp, 2003: 20).

$\mathrm{Bu}$ koşullar altında göçmen ailelerden gençlerin durumu kendilerinden bir veya iki kuşak öncekilerden çok farklı değildir. İşsizlik oranlarına bakıldığında göçmenler arasında işsizliğin hemen hep Almanlar arasındaki işsizliğin iki katı civarında olduğu görülmektedir. 1983'de işsizlik Almanlar arasında \% 6,1 ve göçmenler arasında \% 11,3 oranında iken, 1999'da bu oranlar sırasıyla $\% 8,3$ ve $\% 15,8$ 'dir. $\mathrm{AB}$ üyesi ülkelerden gelen göçmenlerin işsizlik oranları Almanların işsizlik oranlarına oldukça yakın $(\% 8,8)$ iken $\mathrm{AB}$ üyesi olmayan ülkelerden gelenlerde \% 18,9'dur. Aynı durum göçmen gençler için de söz konusudur. 1999'da Alman gençlerde işsizlik oranı \% 7,8, göçmenlerde \% 17,4 ve Türkiye kökenli gençlerde \% 24'dür (Werner, König, 2001: 8,12). Göçmen gençlerin işsizlik oranlarının yüksekliği toplumda saygın bir yere ve kişisel özgüvene sahip olmalarını güçleştirmektedir. Yüksek işsizlik oranlarının gerisinde esas olarak gençlerin eğitim-öğretim sisteminden ve sunduğu firsatlardan yeterince yararlanamaması, dolayısıyla işgücü piyasasına vasıfsız işgücü olarak girmesi yatmaktadır. Piyasa ekonomilerinde eğitim ve öğretim, bireyin işgücü piyasasında değerlendirebileceği beceriler kazanması ve ekonominin sahip olduğu insan kaynaklarını eğitip en optimal biçimde kullanarak dünya pazarlarında rekabet gücünü koruması amaçlarına hizmet eder. Ancak eğitim ve öğretimin amaçları bununla sınırlı değildir. Temel bir insan hakkı olarak eğitim ve öğretim bireysel düzeyde çocuğun ve gencin kişiliğinin gelişmesine, içindeki yaratıcı potansiyelin gerçekleşmesine katkıda bulunur. Aynı zamanda bir toplumda eğitim ve öğretimin önde gelen işlevi sunduğu yukarı doğru sosyal hareketlilik imkanlarıyla sosyal adaletin gerçekleşmesine katkıda bulunmak olup, özellikle göçmen çocukların ve gençlerin yerli yaşıtlarıyla eşit firsatlara sahip olup olmadığı bu açıdan belirleyicidir. Göçmen gençlerin Alman eğitim sistemi içindeki elverişsiz konumlarından ve dil sorunlarının çözülememiş olmasından ötürü istihdam imkanlarının kısıtlılığı, işgücü piyasasındaki dezavantajlı durumlarının temel kaynağını oluşturmaktadır. 


\section{Eğitim Öğretim Durumu}

Almanya'da 2000 yılı sonu itibariyle 1998534 Türkiye vatandaşı yaşamakta olup toplam göçmenler içindeki oranı \% 28'dir. Ancak bu sayıya geçmişten bu yana Alman vatandaşlığına geçmiş olan 424562 kişi de dahil edildiğinde Almanya'da yaşayan Türkiye kökenlilerin sayısı 2,5 milyona yaklaşmaktadır. Göçmen olarak yaşayanların \% 26's 0-14 yaş arasında, \% 29,4'ü 15-29 yaş arasındadır (ÇSGB, 2002: 37,40). 6 yaşın altındaki nüfus içinde Türk nüfusun payının göreli yüksekliği $10-15$ yıl sonra işgücü piyasasına girenler arasında bu grubun oranının özellikle yüksek olacağına işaret etmektedir. Bu nedenle bu çocukların ve gençlerin daha iyi eğitim ve mesleki öğretim koşullarına kavuşmasını sağlayacak yatırımlar yapmak büyük önem kazanmaktadır (Hönekopp, 2003: 5).

1 Ocak 2000 tarihinde yürürlüğe giren yeni vatandaşlık yasasına göre ebeveynlerden birinin sekiz yıldır yasalara uygun biçimde Almanya'da yaşaması durumunda doğan çocuklar Alman vatandaşı olarak kabul edilmektedir. Bunun sonucunda 1999'da Almanya'da doğan yabancı çocuk sayısı 95216 iken, 2000'de eski yasaya göre 91026 olacak bu sayı 50 205'e düşmüştür (Boos-Nünning, 2003:1). Bundan böyle göçmen ailelerden gelen çocuklara ilişkin bilgi toplamak daha zor olacak, ancak Alman vatandaşl1ğını kazanma göçmen ailelerden çocuk ve gençlerin durumunun otomatikman düzelmesine yol açmayacağı için bu kesime yönelik özel önlemler alınmasının gerekliliği devam edecektir.

1999-2000 öğretim yılında göçmen ailelere mensup 1663535 çocuk ve genç Almanya'da okula devam etmektedir. Türkiye'li gençlerin sayısı 503043 ve göçmen gençler içindeki payı \% 30,2'dir. Gençlerin devam ettikleri okul türüne göre dağılımlarına bakılmadan önce üçlü bir yapısı olan Alman okul sistemine dair kısa bir bilgi vermek yararlı olacaktır. Öğrencilerin ilkokul dördüncü sinıftan sonra hangi tür okula devam edeceğinin belirlendiği bu sistemde en alt düzeyde 'Hauptschule' bulunmakta, 10. sinıftan sonra mezun olan gençler çıraklık eğitim yeri bulma şanslarının iyice azaldığı koşullarda vasıfsız işgücü olarak işgücü piyasasına katılmaktadır. 'Realschule' mezunları meslek yüksek okullarına devam etme fırsatı bulmakta, 'Gymnasium'u bitirenler ise üniversiteye gitmeye hak kazanmaktadır. 'Gesamtschule' üç tip okulu bünyesinde barındırmakta ve öğrencilere başarı düzeylerine göre üç diplomadan birini vermektedir. 'Sonderschule' ise öğrenme güçlüğü bulunan zeka özürlü çocukların gittiği okullardır. Alman eğitim sisteminde kökleşmiş olan düşünce çocukların en iyi şekilde yaşa ve öğren- 
me becerisine göre homojen gruplarda öğretim göreceğidir. Bu yaklaşım ifadesini okul tipine göre üçlü dikey dağılımda bulmakta ve çocuklar sadece bir üstten daha alttakine geçiş yapabilmekte ama neredeyse hiç alttan üste doğru hareketlilik yaşanmamaktadır (Neumann, 2003).

Tablo: Seçilmiş okul türlerinde Alman ve göçmen gençlerin dağılımı (\%)

\begin{tabular}{|l|l|l|l|l|}
\hline Okul türü & \multicolumn{2}{|c|}{ AIman öğrenciler } & \multicolumn{2}{c|}{ Göçmen öğrenciler } \\
\hline & 1994 & 1997 & 1994 & 1997 \\
\hline Toplam & 100,0 & 100,0 & 100,0 & 100,0 \\
\hline Hauptschule & 10,1 & 9,9 & 24,1 & 21,1 \\
\hline Realschule & 12,0 & 12,4 & 8,7 & 8,3 \\
\hline Gymnasium & 23,3 & 23,0 & 9,5 & 9,2 \\
\hline Gesamtschule & 5,5 & 5,9 & 6,6 & 6,8 \\
\hline Sonderschule & 3,7 & 3,6 & 6,1 & 6,2 \\
\hline
\end{tabular}

Kaynak: Beauftragte, 2000: 114

1997 yılında Alman okullarına devam eden göçmen öğrencilerin toplam öğrenciler içindeki oranı \% 9,4 olup, bu öğrencilerin \% 79,7'si genel okullara, \% 20,3'ü mesleki okullara gitmektedir. Alman gençleriyle kıyaslandığında göçmen gençlerin Hauptschule'lerde yoğunlaştığı ancak Gymnasium'larda düşük oranda yer aldıkları görülmektedir. Her dört Alman öğrenciden biri Gymnasium'a giderken, göçmen gençlerde bu, her dokuz öğrenciden biri olmaktadır. Sonderschule'lerde de göçmen gençler Almanlara kıyasla daha yüksek oranda bulunmaktadır.

Okul mezuniyet durumlarına bakıldığında, 1997'de göçmen gençlerin $\%$ 42,7'si Hauptschule diploması alırken, bu oran Alman gençlerde \% 25,2'dir. Buna karşılık her dört Alman gençten biri $(\% 25,5)$ Gymnasium diploması alırken bu oran göçmen gençlerde onbirde birdir (\% 9). Realschule diploması alanların oranı Almanlarda \% 40,9, göçmenlerde \% 28,1'dir. Yine aynı yıl her beş göçmen gençten biri $(\%$ 19,4) herhangi bir diploma almadan okul sisteminden ayrilırken, Almanlar arasında bu durumda olanlar onüçte birdir $(\%$ 7,7) (Beauftragte, 2000: 116). Alman ve göçmen gençler arasındaki eğitim açı̆̆ı kapanma eğiliminde olmadığı gibi bu durum göçmen gençlerin mesleki öğretime veya yüksek öğretime geçmesinde ciddi zorluklar yaratmaktadır. 
Aynı şekilde mesleki öğretim ile ilgili istatistiklere daha yakından bakıldığında, göçmen gençlerin temel meslek öğretiminde yoğunlaştıkları, bunu izleyen daha üst meslek eğitim okullarında Almanlara kıyasla düşük oranda yer aldıkları görülmektedir (Granato, Werner, 1999). Çıraklık eğitim yerleri için rekabetin arttığı koşullarda, Realschule ve Gymnasium diploması olanların karşısında Hauptschule mezunu olan göçmen gençlerin hiç şansı bulunmamaktadır. Göçmen gençlerin işyerindeki çıraklık eğitimindeki payları 1994'den 1997'ye gerileme içinde olup, 1994'de \% 44 olan bu oran 1997 'de \% 37'ye düşmüştür. 15-18 yaş grubundaki göçmen gençlerin \% 37'si bir çraklık eğitim yerine sahipken bu oran Alman gençlerde \% 60,8'dir (Beauftragte, 2000: 255) Çıraklık eğitim yeri cinsiyet bakımından da önemli farklar göstermekte ve göçmen genç kızlar bu durumdan daha olumsuz etkilenmektedir. 1997'de genç erkeklerin \% 43'ü çıraklık eğitimi görürken, bu oran genç kızlarda \% 31'dir. Bu düşük oranların yanı sıra göçmen gençlerin meslek eğitimi gördükleri alanlar çok daha sınırlıdır, onlar ancak Alman gençler için cazip olmayan alanlarda çıraklık eğitim yeri bulabilmektedir. Genç kızların \% 18'i kuaför, \% 10,9'u doktor yardımcısı, \% 10,8'i dişçi yardımcısı ve genç erkeklerin \%9'u araba tamircisi, \% 7,4'ü elektrik tesisatçısı, \% 9,8'i gaz ve su tesisatçısı, \% 8,6'sı boya ve cilacı, \% 7,8'i perakende ticarette tezgahtar olarak eğitilmektedir (Beauftragte 2000: 257, Granato, 2000: 11). Bu mesleklerin genel özelliği öğretimin bitmesinden sonra vasıflı işçi olarak o işyerinde istihdam imkanının azlığı, işi kaybetme riskinin yüksekliği, düşük ücret ve düşük kariyer imkanları ve kötü çalışma koşullarıdır. Göçmen gençlerin özellikle kamu hizmetlerindeki çıraklık eğitim yerlerinde son derece düşük oranda bulunduğu görülmektedir; tüm öğretim görenlerin sadece $\% 3,1$ 'i göçmen gençlerdir. Çok kültürlü ve çok dilli uzman personele ihtiyaç duyulan iktisadi alanlarda, kişisel hizmetlerde ve hatta müşterilerin çoğunun yabancı olduğu dallarda, ör. danışmanlık kurumları, bankacılık ve sigortacılık hizmetlerinde bile göçmen gençlere çıraklık eğitiminde yeterince yer verilmemektedir. Öte yandan 1998'de 20-29 yaş arasındaki mesleki eğitimi olmayan göçmenlerin oranı $\% 40$ (erkeklerde $\% 37$, kadınlarda \% 43) iken, aynı yaş grubundaki Almanlarda bu oran $\%$ 12'dir (erkeklerde \% 10, kadınlarda \% 13) (Granato, 2000: 24). Bütün bunlar ihtiyaç duyulan işgücünün vasıflılık düzeyinin sürekli arttığı bir toplumda, göçmen gençlerin yeni yaratılan iş imkanlarından yararlanamamasına, sadece sınırlı sayıdaki vasıfsız işlerde yoğunlaşmasına ve işsizlikten en fazla etkilenmesine yol açmaktadır.

Göçmen gençler ülkeleri kökeninde ayrıştırılarak ele alındığında Türki- 
ye kökenlilerin en elverişsiz durumda oldukları ortaya çıkmaktadır. Ancak bu durum hiç bir şekilde bu gruptaki göçmen gençlerin bireysel ve ailesel yaklaşımlarıyla ilgili değildir. Gençlerin özellikle genç kızların mesleki eğitime yönelik motivasyonlarının çok yüksek olduğu ancak ekonomideki dalgalanmalara bağlı olarak mesleki eğitim yerlerinin sayısında görülen azalma, işverenlerin önyargıları ve ayrımcı tutumları, okul diplomalarının düzeyinin göreli düşüklüğü ve kimi durumlarda dil yetkinliğinin yetersizliği nedeniyle Alman gençlerle eşit firsatlara sahip olmadığı görülmektedir. Gençlerin iki dilli ve çok kültürlü olmalarının getireceği yararlar henüz bu özelliklere ihtiyaç duyan işletme sahipleri tarafından bile yeterince algılanmamaktadır (Beauftragte, 2000: 128-129, Granato, 2000).

\section{Dilin Önemi}

Göçmen ailelerin çocuklarının ve gençlerinin okuldaki ve mesleki eğitimdeki başarıları açısından Almanca dil bilgisinin önkoşul olduğu, yetersiz dil bilgisinin özgüveni sarstığı, bireyin yaşam firsatlarını azalttığı bilinmektedir. Göçmen ailelerin çocukları ve gençleri Almancaları itibariyle kendi içinde büyük farklılıklar gösterirken, dil etkinliği bakımından (gramer, kelime hazinesi, yazılı ifade vb.) bireysel farklılıklar eğitimde başarı düzeyi üzerinde belirleyicidir. Ancak sadece göçmen gençlerin dil sorunlarıyla ve eğitim sistemine uyumlarıyla sınırlı kalmayarak eğitim sistemine bakıldığında şunlar görülmektedir: Öğrencilerin önemli bir kısmının çok dilli olmasına karşın Almanya'daki cğitim sistemi tek kültürlü ve tek dillidir. Okullardaki müfredat genel olarak Almanca'yı ikinci dil olarak öğrenen çocuklara göre hazırlanmamıştır. Göçmen çocuklarla çalışan öğretmenler buna göre eğitilmediğinden zorluklarla karşılaşmaktadır. Derslerde iki veya çok dillilik çoğunlukla bir değer olarak tanınmamakta ve desteklenmemektedir.

Göç araştırmalarının uzun zamandır ortaya koyduğu gerçek birinci dilin düzeyinin ikinci dilin varabileceği düzey üzerinde belirleyici olduğudur. Eğitim bilimcileri Almanca'nın iyi öğrenilebilmesi için ana dili iyi bilmenin önemine dikkat çekmektedir. Bu nedenle Almanca'nın ikinci dil olarak öğrenilmesi erken yaşlarda başlayan ve bir hedefe yönelik olan didaktik bir dil desteği gerektirmektedir. Dengeli bir iki dillilik hedefinde çocuğun bilişsel gelişimi açısından ana dilin önemi göz önüne alındığında, ana dilin geliştirilmesinin gerekliliği ortaya çıkmaktadır (Neumann, 2003). Böylece çocukların daha iyi Almanca öğrenmelerini sağlamak için de ana dilin öğrenim sürecine katılması gereklidir. Almanya'da göçmen çocukların dil bil- 
gilerini geliştirmek için eyaletler arasında farklı uygulamalar vardır. Bazı eyaletlerde ana dil eğitimine ilişkin dersler okul saatleri içinde yer alsa da, çoğunlukla bu konu göçmen gönderen ülke konsolosluklarının sorumluluğunda olmakta ve okul saatlerinin dişında düzenlenen derslere katılım düşük düzeyde kalmaktadır. Farklı koşullar ve dil öğrenmenin sınırlı imkanlarına bağlı olarak çocuklar ne Almanca'yı, ne kendi ana dillerini yeterli düzeyde öğrenememektedir. İki dilden daha fazla dilin konuşulduğu ortamlarda büyüyen çocuklarda sorunlar daha da artmaktadır. Çok dilliğin yarattığı sorunlar genellikle anlaşılmamakta ve dile bağlı yetersizlikler kolaylıkla öğrenme güçlüğü olarak tanımlanarak çocukların düzeylerinin altındaki okullara, özellikle Sonderschule'ye gönderilmelerinde etkili olmaktadır. Federal Almanya hükümetinin yabancılar sorumlusunun yayınladığı raporda sorunlar böyle saptanmakta ve çocukların küçük yaştan itibaren dil öğrenmelerinin desteklenmesi gerektiği belirtilerek, iki veya çok dilliğin sunduğu potansiyelin değerlendirilmesi, ana dil öğretimine ilişkin derslerin düzenli programa dahil edilmesi, iki dilde öğretim yapan Avrupa Okulları gibi model okulların desteklenmesi önerilmektedir. Bu amaçla eğitim, öğretim personeli buna uygun müfredata sahip olan programlarda eğitilmeli, veliler mevcut okul sistemi üzerine daha çok aydınlatılmalı ve genç annelerin Almanca bilgilerini iyileştirecek programlar konulmalıdır. Ancak bunlar tavsiye olmanın ötesine pek geçmemektedir (Beauftragte, 2000: 119-122).

\section{PISA Araştırması ve Almanya'nın Eğitim-Öğretim Açısından Durumu}

2000 yılında yapılan ve Almanya'da büyük yankılar uyandıran PISA araştırması 32 ülkede 15 yaşındaki 265000 öğrenciye uygulanmış bir anket çalışması olup, öğrencilerin başarı düzeyini okuma/anlama, matematik, fen bilgileri yetkinliği itibariyle karşılaştırmıştır. Araştırmanın amacı zorunlu eğitimin son yılındaki öğrencilerin topluma aktif katılım potansiyeli açısından mevcut durumunu açığa çıkarmak ve eğitim, öğretim politikaları itibariyle hükümetlere yol göstermektir. Bu sinav Almanya'da temsili örneklem çerçevesinde 219 okulda 5000 öğrenciye uygulanmıştır. Okuma/anlama yetkinliğiyle karmaşık bir metnin anlaşılması, ana fikrin çıkarılması, soruları yanıtlayacak bilgilerin edinilmesi, günlük hayata dair bilgiyle metnin sunduğu bilgiler arasında bağlantı kurulması kastedilmektedir. Almanya okuma/anlama yetkinliği sınavında 22. sırada gelmiştir. İlk sırayı Finlandiya almıştır. Beş farklı yetkinlik düzeyi çerçevesinde öğrencilerin sınıflandırılmasına bağlı olarak Almanya'da en alt basamağın altında kalanların oranı $\% 10$ olup (OECD ortalaması \% 6), Almanya'nın gerisinde bulunan ülkeler 
Brezilya, Meksika, Lettland ve Lüksemburg'dur. Öğrencilerin \% 13'ü en alt basamakta bulunmaktadır ve bu durum \% 23 oranında öğrencinin sadece temel düzeyde okuyup anlayabildiğine işaret etmektedir. Öğrencilerin \% 42'si boş zamanlarında keyif için kitap okumadığını söylemiştir. Bu, diğer ülkelere kıyasla en yüksek orandır (Artelt vd., 2002: 16-17)

Matematik yetkinliği matematiğin dünyada oynadığı rolü bilmek ve anlamak, temellendirilmiş matematiksel yargılarda bulunmak ve angaje bir vatandaş olarak yaşamanın gereklerini yerine getirmek olarak tanımlanmıştır. Almanya siralamada 21. olup, öğrencilerin dörtte biri yine en alt basamakta ve onun da altında yer almaktadır. Bu öğrencilerin bilgileri ancak bir meslek öğretimi görmelerine yetecek düzeydedir. Bu sınavda ilk sırayı alan ülke Japonya, ikinci sırayı alan ülke Güney Kore'dir (Artelt vd., 2002: 23).

Fen bilgileri sınavı ise soruları tanıma, sonuç çıkarma ve okulda bu alanlarda öğrenilenlerin giderek daha fazla bilimsel ve teknik ilerlemeye dayanan bir dünyada ne ölçüde kullanılabildiğini test etmeyi amaçlamaktadır. Sınav sonuçlarına göre ilk sırada Güney Kore, ikinci sırada Japonya gelmektedir. Almanya 21.sırada olup, en alt basamaktaki öğrenci oranı \% 26,3 'dir. Oysa İngiltere'de bu oran \% 13,5'dir. Her üç sınav açısından da öğrencilerin başarı düzeylerinin OECD ülkelerinin ortalamasının altında olduğu görülmektedir. Ayrıca başı çeken ülkelerde en iyi ve en kötü öğrenci kategorileri arasındaki farkın az olduğu, oysa Almanya'da en başarılı ve en başarısız öğrenciler arasındaki açığın çok yükssek olduğu saptanmıştır. Almanya'da zayıf öğrencilerin yeterli düzeyde desteklenmediği sonucu ortaya çıkmaktadır (Artelt vd., 2002: 28-30). •

Bu sonuçlar Almanya'da büyük tartışmalara yol açmış, göçmen gençlerin de araştırmaya dahil olmasından ötürü Almanya'nın sıralamadaki geri durumunun bu gençlerin başarısızlığına bağlı olduğuna dair görüşler dile getirilmiştir. Ankete katılan öğrencilerin \% 21,7'sinin ailesinde ebeveynlerden en az biri Almanya dışında doğmuştur. Bu ebeveynlerin üçte ikisi işçi olarak çalışmaktadır ve yarısı vasıfsız işçi konumundadır (Artelt vd., 2002: 34). Bu noktada asıl önem taşıyanın öğrencinin ailesinin ait olduğu sosyal sınıf ve tabaka olduğu görülmektedir. Değişik sosyal kökenden gelenler arasında okuma/anlama yetkinliği itibariyle önemli farklar vardır. En alt basamağı aşamayanlar en fazla alt sosyal tabakalardan gelenler arasındadır. Rutin hizmet işlerinde, vasıflı ve vasıfsız işlerde çalışan iş̧iler ile kendi hesabına çalışanların ailelerinden gelen gençlerin \% 25-40 arasında değişen bir kısmı en alt basamaktadır. Göçmenlik durumunun etkisinin çok sınırlı 
olduğu görülmektedir, çünkü ebeveynlerin her ikisinin de Almanya'da doğmuş olduğu ailelerde bu oran yine \% 20-40 arasındadır (Artelt vd., 2002: 37). Bu dağılım matematik ve fen bilgileri yetkinliği açısından da aynıdır. Sonuç olarak ait olunan sosyal tabaka ile tüm alanlarda sahip olunan yetkinlik arasında doğrudan bağlantı olduğu açığa çıkmaktadır. Nitekim ailenin ait olduğu sosyal tabaka ve çocuğun gittiği okul ilişkisine bakıldığında, en üst meslek grubunda olanların (yöneticiler, akademisyenler, işverenler vb.) çocuklarının \% 52'si Gymnasium'a, \% 29'u Realschule'ye ve \% 10'u Hauptschule'ye gitmektedir. Buna karşılık vasıfsız işçi ailelerinin çocuklarinın \% 42'si Hauptschule'ye, \% 29'u Realschule'ye, \% 10'u Gymnasium'a ve \% 7'si Sonderschule'ye gitmektedir (Artelt vd., 2002: 36).

Almanya en üst ve en alt sosyal tabakadan gençler arasında okuma yetkinliği itibariyle en fazla farkın bulunduğu ülkedir (Artelt vd., 2002: 41). Almanya'da ailenin sosyal konumuyla öğrencinin yetkinlik düzeyi arasında çok sıkı ilişki varken, başka ülkelerde sosyal kökenin etkisinin çok daha s1nırlı olduğu görülmektedir. Çünkü bu ülkelerde sosyal açıdan zayıf tabakalardan gelen çocuklar okul sistemi içinde desteklenmektedir. Almanya'da da sosyal farklılıkların azaltılması ve daha yüksek bir yetkinlik düzeyine ulaşılması alt sosyal sınıf ve tabakalardaki okuma yetkinliğinin artırılmasına bağlıdır.

Bir diğer önemli fark öteki OECD ülkelerinde öğretim kurumlarının daha eşitlikçi yapıda olması ve öğrencilerin zorunlu ilköğretimden sonra hangi okula devam edeceğinin 7., 8. ve hatta 9. sinıftan sonra belirlenmesidir. Oysa Almanya'nın okul sisteminde çocukların dört yıllık temel eğitimden sonra öğretimlerinin çok erken bir aşamasında Gymnasium, Realschule veya Hauptschule'den hangisine gideceğinin belirlenmesi, aşağı doğru kayışın her zaman mümkün ancak yukarı doğru çıkışın neredeyse imkansız olduğu katı bir yapıyı ortaya çıkarmaktadır. Bu erken dağılımın sonuçlarından biri gençlerin sosyal ayrışması olmaktadır. Gymnasium'ların \% 40'ında öğrencilerin çoğunluğu üst orta sinıflardan iken, Sonderschule'lerde ve bir kısım Hauptschule'lerde öğrencilerin çoğunluğu alt gelir grubundan ve sosyal açıdan zayıf ailelerdendir.

Ailenin göç statüsüyle bağlantılı olarak okul durumuna bakıldığında ebeveynlerin her ikisinin Almanya'da doğduğu ailelere mensup gençler ile ebeveynlerden birinin Almanya'da doğduğu ailelerdeki gençlerin gittikleri okullar arasında fazla fark olmadığı ve çoğunluğun Gymnasium ve Realschule'ye gittiği görülmektedir. Buna karşılık ebeveynlerden hiç birinin Al- 
manya'da doğmadığı ailelerde çocuklarının yarısı (\% 49) Hauptschule'ye, \% 28'i Realschule'ye, \% 15'i Gymnasium'a gitmektedir. Göçmen kökeni olan ailelerde eğer her iki ebeveyn de Almanya'da doğmuş ise çocuklarının okuma yetkinliği itibariyle kategorilere dağılımı Alman ailelerinkinden farklılık göstermemektedir. Ancak ebeveynlerin her ikisi de Almanya dişında doğmuş ise çok zayıfların oranı \% 20 olup, gençlerin \% 50'si en alt basamağı geçememektedir. Oysa bu öğrencilerin \% 70'i başından beri Alman okul sistemine dahil olmuştur (Artelt vd., 2002: 38-39). Dildeki yetersizlik diğer derslerdeki başarı düzeyini de olumsuz etkilemektedir. Ancak göçmen gençler dahil edilmediğinde Almanya okuma/anlama yetkinliğinde sadece bir sıra ilerleyerek, 22 'den 21. sıraya gelmektedir. PISA araştırmasının ortaya koyduğu gerçek Alman eğitim sisteminin öğrencilerin heterojen yapısıyla baş edememesidir. Oysa öğrenci yapısının aynı ölçüde heterojen olduğu İsveç bu konuyu öğrencilere kendi ana dillerini öğreterek çözmüştür ve ülkeler sıralamasında 8.dir (Neumann, 2003: 8).

\section{İki Dilli Eğitimin Önemi}

Bir göç ülkesi olduğunu ve bundan sonra da demografik özellikleri nedeniyle olmaya devam edeceğini yeni yeni kabullenen Almanya'da çok dilliğin getirdiği potansiyel henüz anlaşılmamıştır. Alman eğitim sisteminin Almanya'nın bir göç ülkesi olduğu ve bu ülkede bir çok dilin konuşulduğu olgusuna göre düzenlenmesi gerekmektedir. Eğitim sistemi hem göçmen hem yerli halkın çocuklarına ve gençlerine sosyal, dilsel ve kültürel açıdan heterojenliğe uyum göstermeyi öğretmek durumundadır. Bunun yolu tüm çocukların iki dilli yetiştirilmesinden geçmektedir.

Uluslararası çok dillilik araştırmalarının bulgularına göre çok dilli toplumlarda istendiği takdirde çocukların iki dilde yetişmesinin toplum yararına olacak şekilde düzenlenmesi mümkündür. İki dilde yetişen çocuklar kafalarında iki ayrı dil sistemine sahip değildir, onlar iki dili tek bir sistemin bileşenleri olarak görürler. İki dilde büyümek dil öğrenimi açısından bir sorun yaratmaz. Sorun olan, tek dilliliği normal olarak görüp, diğer her şeyin buna uyması gerektiğine dair tarihsel olarak belirlenmiş inançtır. Bu inancın terkedilmesiyle okula gidene kadar edinilen iki dilliliğin negatif değerlendirilmesinden ve okul başarısına engel olarak görülmesinden vazgeçilebilir. Aksi yaklaşım ciddi bir kaynağın israf edilmesi demektir. Zaten bir çok eyalette üçüncü sınıftan itibaren İngilizce dersinin konması tam da çocukları iki dilli yetiştirme amacına yöneliktir. Bu yüzden okulun çocuğun sahip olduğu dil hazinesini geliştirmesini talep etmek gerekmektedir. Yani 
yeterince uzun bir sürede iki dilde okuma yazmayı öğrenmesi, ana dilde derslerin yapılması ve anadilin derslerle sistemli bağlantısının kurulması gereklidir. Tatmin edici bir iki dilli gelişme ancak toplumsal olarak bu dillere değer verilmesi, dille duygusal olarak pozitif içerikli bağlantı kurulması, destekleyici bir okul öğretimi ve yönlendirici bir aile eğitimiyle mümkündür (Neumann, 2003:11).

İki dilli eğitim konusunda yapılması gerekenler eğitim-öğretim sisteminde köklü bir dönüşümü gerektirmektedir ve uzun vadelidir. Ancak kısa ve orta vadede işgücü piyasasında göçmen gençlerin durumunu iyileştirmek için yapılması gerekenler vardır ve bunların başında öğrencilerin $\mathrm{Al}-$ mancayı daha yetkin düzeyde öğrenebilmeleri için alınacak önlemler ve destek programları gelmektedir. Almanca toplumdaki temel iletişim ve öğrenme aracı olarak sadece kendi başına başarılması gereken bir ders değil aynı zamanda diğer derslerdeki başarının da temel belirleyenlerindendir. $\mathrm{Bu}$ nedenle sosyal açıdan dezavantajlı çocukların ve göçmen ailelerin çocuklarının Almanca dil bilgilerini okulda geliştirmek büyük önem taşımaktadır. Ayrıca aktif istihdam politikaları çerçevesinde, mezun olmadan okuldan ayrılmış veya çıraklık eğitim yeri bulamamış gençlere yönelik özel programlar geliştirilmesi, kamu hizmetlerinde daha fazla göçmen gencin çıraklık eğitimine alınarak daha sonra istihdamı yönündeki uygulamaların yürürlüğe konmasında yarar vardır. 


\section{Kaynaklar}

ARTELT C., Baumert, J., Klieme E., Neubrand M., Prenzel, M., Schiefele U., Schneider, W., Schümer, G., Stanat, P., Tillmann, K.J., Weiss, M. (Der.) PISA 2000 Zusammenfassung zentraler Befunde, (http://www.mpib-berlin.mpg.de/pisa-ergebnisse.pdf)

Beauftragte der Bundesregierung für Ausländerfragen (2000) Bericht über die Lage der Ausländer in der Bundesrepublik Deutschland, Berlin.

BOOS-Nünning U. (2003) Junge Migranten und Migrantinnen türkischer Herkunft in Deutschland: Gesellschaftliche Integration, Almanya-Türkiye Göç İlişkilerinde Yeni Gelişmeler Uluslararası Seminerine sunulan bildiri, İstanbul Bilgi Üniversitesi, 24-25 Ocak 2003.

Çalışma ve Sosyal Güvenlik Bakanlığı (2002) 2000-2001 Raporu, Yurtdışındaki Vatandaşlarımıza İlişkin Gelişme ve Sayısal Bilgiler, Ankara.

GRANATO M. (2000) "Jugendliche ausländischer Herkunft in der beruflichen Ausbildung", Ausbildungschancen Jugendlicher ausländischer Herkunft, BIBB, Bonn.

GRANATO M. \& WERNER, R. (2000) Ausländische Jugendliche in Deutschland-Sinkende Ausbildungschancen für Jugendliche mit ausländischem Pass:motiviert, engagiert und dennoch weniger Chancen?, Ausbildungschancen Jugendlicher ausländischer Herkunft, BIBB, Bonn.

HÖNEKOPP E. (2003) Non-Germans on the German Labour Market, AlmanyaTürkiye Göç İlişkilerinde Yeni Gelişmeler Uluslararası Seminerine sunulan bildiri, İstanbul Bilgi Üniversitesi, 24-25 Ocak 2003.

NEUMANN U. (2003) Mehrsprachigkeit als Ressource im Bildungsprozess, Almanya-Türkiye Göç İlişkilerinde Yeni Gelişmeler Uluslararası Seminerine sunulan bildiri, İstanbul Bilgi Üniversitesi, 24-25 Ocak 2003.

WERNER R. (2000) Ausländische Jugendliche in Deutschland. Zahlen/Statistiken, in Ausbildungschancen Jugendlicher ausländischer Herkunft, BIBB, Bonn.

WERNER H., \& KÖNIG I., (2001) Integration ausländischer Arbeitnehmer in die Arbeitsmärkte der EU-Länder, Bundesanstalt für Arbeit, Diskussionsbeiträge, Ausgabe Nr.10/21.8.2001, Nürnberg. 